\title{
UM OLHAR SOBRE A LINGUAGEM ESCRITA \\ E OS PROCESSOS DE REFERENCIAÇÃO EM CARTAS NOTARIAIS ${ }^{1}$
}

\author{
Jaqueline Aparecida dos Santos Dutra ${ }^{2}$ \\ Elódia Constantino Roman ${ }^{3}$
}

\begin{abstract}
Resumo: Para um trabalho satisfatório com a escrita, não basta tê-la somente como instrumento de comunicação, visto que o processo de apropriação da linguagem por meio da escrita envolve muitos aspectos além do conhecimento do alfabeto ou o dominio da técnica. Assim, o objetivo deste trabalho é refletir sobre a importância da escrita na constituição dos sujeitos e da sociedade. O foco está nas escolhas linguísticas e nas estratégias de referenciação textual empregadas na construção do documento denominado carta notarial, produzido no ano de 1803. Com base em Fisher (2009), Olson (1997), Bourdieu (1998), Mondada \& Dubois (2003), Koch (2008), entre outros, observou-se como a escrita é compreendida sob diferentes perspectivas. Os resultados obtidos revelam que a seleção lexical na linguagem escrita é realizada com base nas intenções do autor do texto perante seu interlocutor. Da mesma forma, atuam como elementos instituidores de valores e crenças individuais e coletivas.
\end{abstract}

Palavras-chave: Linguagem escrita. Prática social. Referenciação.

\section{INTRODUÇÃO}

Uma reflexão acerca da trajetória dos estudos sobre a escrita possibilita observar que são muitas as perspectivas que já foram adotadas. Primeiramente, era o interesse histórico que movia os estudiosos, o desejo de desvendar a origem e compreender a evolução dos sistemas de escrita. No entanto, a limitação dos estudos somente a esse campo impedia o acesso a outras especificidades da escrita e, por esse motivo, as investigações passaram a abordar aspectos cognitivos e sociais envolvidos na produção dessa modalidade linguística.

\footnotetext{
1 Parte deste trabalho foi apresentada oralmente no VII Congresso Internacional da Abralin Curitiba, 2011. Uma versão consta nos Anais do evento, disponível em CD-ROM. ISSN 2179-7145.

2 Aluna do Programa de Mestrado em Linguagem, Identidade e Subjetividade, da Universidade Estadual de Ponta Grossa (PR) - UEPG. Bolsista CAPES. Email: jaquelineasdutra@yahoo.com.br.

${ }^{3}$ Professora Adjunto - D, Programa de Mestrado em Linguagem, Identidade e Subjetividade, da Universidade Estadual de Ponta Grossa (UEPG). Doutora em Linguística e Língua Portuguesa pela Universidade Estadual Júlio de Mesquita Filho. Email: ecroman61@yahoo.com.br.
} 
Sabe-se que novas formas de observação resultaram em diferentes visões sobre a escrita. Seja como recurso de preservação da memória, instrumento de comunicação, como forma de inclusão ou exclusão social, etc., ela se apresenta como um campo de pesquisa aberto e representativo dentro dos estudos da linguagem. Isso viabiliza amplas discussões, principalmente no que diz respeito à relação existente entre a escrita e a sociedade.

Segundo Olson (1997), é desaconselhável afirmar que haja um vínculo direto entre a escrita e o progresso social, cultural e científico, pois não há comprovação de que o domínio da escrita promova tais avanços. No entanto, é com base nessa e em outras crenças apontadas pelo autor que muitos governos direcionam suas ações, principalmente com relação à alfabetização. A aquisição da escrita, quando entendida como simples domínio do código, acaba propiciando uma perda enorme ao sujeito usuário da língua, por impossibilitar que ele de fato se aproprie dela.

Levando-se em conta esse fato, destaca-se que o objetivo do trabalho é refletir a respeito da relevância da escrita na constituição dos sujeitos e da sociedade, certificando o seu caráter social. Com efeito, parte-se da identificação e análise do processo de referenciação textual, considerando-o como uma "prática simbólica" (MONDADA; DUBOIS, 2003) e como uma "atividade discursiva" (KOCH, 2008).

A investigação apresentada está pautada na análise do documento denominado carta notarial produzida no ano de $1803^{4}$, na cidade de Antonina, Paraná. Esse documento é procedente do arquivo público de São Paulo e faz parte do material editado pelos pesquisadores do projeto PHPP - Para História do Português Paranaense: estudos diacrônicos em manuscritos dos séculos XVII a XIX ${ }^{5}$, da Universidade Estadual de Londrina. O intuito do projeto é a construção da história linguística do Estado do Paraná e da própria sociedade paranaense.

\footnotetext{
${ }^{4} \mathrm{O}$ trecho anexado ao presente artigo corresponde aos docs. 437 a 441, compreendendo uma parte dos dados investigados. Trata-se da carta do Bispo Dom Matheos, um dos textos que compõe a carta notarial $\mathrm{n}^{\circ} 12$, que tem como assunto o pagamento de vários impostos à Igreja pelos fiéis, do qual foram retirados os exemplos apresentados.

${ }^{5}$ Os documentos editados pelo PHPP correspondem a cartas trocadas entre as autoridades da época que tratavam de assuntos referentes às antigas vilas do litoral do Paraná. Os estudos realizados resultaram no livro Scripturae nas Villas de São Luiz de Goaratuba e Antonina: manuscritos setecentistas e oitocentistas (BARONAS; AGUILERA, 2007).
} 
Na primeira seção, com base em Higounet (2003), Fischer (2009), Bourdieu (1998), Olson (1997), são discutidos alguns aspectos a respeito da evolução e do desenvolvimento dos estudos sobre a escrita, ressaltando a sua função sociointeracionista e sua relevância como forma de manifestação da linguagem.

$\mathrm{Na}$ seção seguinte, o foco são os processos de referenciação textual, destacando a importância das escolhas linguísticas como um meio produtivo para que os sujeitos se apropriem da linguagem escrita, considerando as especificidades do material analisado. O aporte teórico adotado para a reflexão compreende os estudos de Bakhtin (2003), Mondada e Dubois (2003), Koch (2009), entre outros.

Por fim, nas considerações finais, busca-se reiterar a analogia entre a escrita e a sociedade, destacando as escolhas linguísticas no processo de referenciação textual como estratégias discursivas que reforçam o aspecto social da linguagem escrita.

\section{ALGUMAS CONSIDERAÇÕES SOBRE A ESCRITA}

Apesar da importância atribuída à escrita pela sociedade moderna, constata-se que tanto a oralidade quanto a escrita são temas que mobilizam muitos pesquisadores da linguagem. Olson e Torrance (1997), Gnerre (2009), Marcuschi (2010) são apenas alguns dos estudiosos que, em suas investigações, não buscam defender uma ou outra modalidade linguística, mas destacar a importância das duas tanto sob a perspectiva de comunicação, como do ponto de vista do letramento ${ }^{6}$.

Da mesma forma, a discussão que se propõe neste trabalho não pretende advogar a favor da linguagem escrita como sendo a melhor ou a mais apropriada modalidade linguística. O que se busca é refletir sobre a interação e a construção de valores sociais por meio da escrita, a partir das escolhas lexicais e estratégicas que são realizadas quando se produz

\footnotetext{
${ }^{6}$ Letramento aqui é visto sob a perspectiva de The New Literacy Studies (STREET, 2003). "Os novos letramentos" são considerados pelo autor a partir da concepção de "múltiplos letramentos", levando-se em conta não somente o tempo e o espaço, mas as relações de poder existentes em situações de ensino e aprendizagem.
}

DUTRA; ROMAN - Um olhar sobre a linguagem escrita... 
um texto. Acredita-se que esse é um modo pelo qual o sujeito pode apropriar-se da linguagem, de acordo com as suas necessidades e objetivos reais de comunicação.

Quando se pensa nas sociedades atuais, não há como negar o lugar privilegiado ocupado pela escrita, a ponto de colocar em condição de inferioridade os sujeitos que a ela não têm acesso. Conforme argumenta Fischer (2009, p.110), "a capacidade de ler e escrever se tornou, no mundo moderno, a segunda capacidade mais importante, perdendo apenas para a aquisição da própria língua". Isso, segundo o autor, torna a escrita indispensável à humanidade.

No entanto, não é de hoje que a escrita tem seu valor reafirmado. A história linguística da humanidade demonstra que, desde os primórdios, o homem manifesta a necessidade de se expressar por meio de sinais e símbolos, elementos que evoluíram com o passar do tempo, dando origem ao alfabeto que conhecemos hoje.

No que se refere à relevância dos elementos gráficos, Fischer (2009, p. 109) destaca que "em algumas culturas, a linguagem escrita alcançou a veneração, como no caso dos hebreus de Canaã [...]". O autor destaca que "a arte gráfica da escrita, e não necessariamente a mensagem transmitida, se tornou algo à parte da existência cotidiana, uma comunicação transcendental a ser praticada apenas por escribas ou sacerdotes".

Fischer aponta para a valorização do código e da grafia de sinais e, a partir disso, outro panorama pode ser vislumbrado: o da escrita como técnica. Bazerman (2006, p. 88), ao se reportar às especificidades históricas do gênero carta, por exemplo, afirma que, por se tratar de um gênero textual bastante difundido desde a antiguidade, ela assume na organização da sociedade um papel importante.

Dentro da Igreja, por exemplo, Bazerman (2006, p. 88) aponta que a carta assume tanta importância que acarreta o desenvolvimento de um ramo da retórica específico para treinar os clérigos no tratamento de assuntos religiosos e administrativos por meio da escritura de cartas. Assim, escrevê-las torna-se uma arte dentro da Igreja, conforme destaca Bazerman (2006), com base em Murphy (1971). O autor também acrescenta que 
os escritores das cartas foram aconselhados a construir um laço de boa vontade com o receptor, invocando sentimento e obrigação, e narrando explicitamente a situação que apresentava a necessidade da carta e a esperada cooperação do receptor. (BAZERMAN, 2006, p. 88)

Outro ponto de destaque no processo evolutivo da escrita corresponde à invenção da imprensa. Segundo Higounet (2003, p. 159), trata-se de um marco para a história da escrita e da humanidade, pois viabiliza a disseminação da linguagem e dos textos escritos. A consequência disso é a padronização do código escrito (alfabeto) e a atuação simbólica da escrita como instrumento de poder, visto que, com a propagação de textos escritos, houve a necessidade de maior acesso e de domínio do código. Assim, a escrita passou a atuar como um mecanismo de inclusão ou exclusão social, ou seja, aqueles que dominam o código escrito, a partir do pensamento moderno, estão propensos a ascender socialmente.

Considerando esses apontamentos, podem-se estabelecer três aspectos que atribuem valor à escrita: o primeiro corresponde à escrita como código; o segundo diz respeito à escrita como técnica; e o terceiro aspecto está afeto às relações de poder que se estabelecem por meio dela. A partir de então, a linguagem corresponde a um discurso.

No que diz respeito ao terceiro aspecto mencionado, verifica-se que apresenta estreita relação com a perspectiva sociointeracionista da linguagem, pois as relações de poder que se estabelecem socialmente tornam-se possíveis somente porque os sujeitos interagem. Assim, a linguagem escrita passa a ser vista como um ato social, e, como tal, não admite somente a consideração de elementos essencialmente linguísticos. Para Bourdieu (1998),

os discursos não são apenas (a não ser excepcionalmente) signos destinados a serem compreendidos, decifrados; são também signos de riqueza a serem avaliados, apreciados, e signos de autoridade a serem acreditados e obedecidos. A língua raramente funciona, na existência ordinária, como puro instrumento de comunicação [...]. (BOURDIEU, 1998, p. 53) 
Os pressupostos de Bourdieu (1998) expõem o caráter que a linguagem apresenta de manifestação de poder. Em sua concepção, o autor relaciona linguagem e "poder simbólico". A escrita eleva o sujeito a um "ser maior", ou seja, o sujeito que tem o domínio da linguagem escrita é investido de uma espécie de superioridade sobre os demais, considerando uma sociedade em que a escrita ocupa um papel central.

Essas e outras condições relativamente complexas que envolvem a linguagem escrita trazem à tona uma questão essencial: no momento da comunicação, no ato de interação entre os sujeitos, aspectos essencialmente linguísticos se juntam a aspectos extralinguísticos. Em virtude disso, Olson (1997, p. 124) afirma que "ao ler um texto escrito, recai sobre o leitor um novo ônus: reconstruir a atitude de quem falou ou escreveu com relação ao texto; e sobre o escritor recai ainda outro novo ônus: caracterizar tal atitude exclusivamente por meios léxicos".

Portanto, parte-se do princípio de que as escolhas linguísticas, ainda que não unicamente, são um ponto importante dentro do processo de produção da linguagem escrita. Obviamente, a seleção feita pelo produtor do texto não consiste na garantia de que ele terá suas metas comunicativas alcançadas. Um texto escrito é sempre uma possibilidade, tanto para quem escreve quanto para quem recebe.

Nesse sentido, deve-se ter presente a relação indispensável entre os elementos linguísticos que compõem o texto e os fatores extralinguísticos que são acionados, tanto no momento da produção quanto no ato de recepção textual. Assim sendo, considera-se que os elementos de referenciação no texto escrito podem atuar como uma forma de minimizar as eventuais lacunas que a escrita possa apresentar, bem como colaborar para que o sujeito alcance seus propósitos comunicativos. 


\section{O PROCESSO DE REFERENCIAÇÃO COMO ESTRATÉGIA PARA A ESCRITA}

Ao tratar a escrita como prática social, é inapropriado deixar de lado os sujeitos da linguagem (locutores e interlocutores), que não podem ser vistos isoladamente. Portanto, olhar para o meio no qual estão inseridos também é indispensável. Desse modo, a escrita, como prática, envolve interação e sociedade.

Nesse sentido, os estudos de Bakhtin são relevantes para este trabalho, uma vez que esse estudioso observa a linguagem a partir de seu caráter interativo. Para o autor, cada enunciado produzido gera, inevitavelmente, uma reação ou uma resposta do receptor. Esse processo de trocas sucessivas entre produtor e receptor de enunciados indica que a linguagem só assume representação dentro de determinado contexto e de situações reais de comunicação.

Nota-se, portanto, que, para o autor, os recursos lexicais, gramaticais e sintáticos da língua somente assumem um valor concreto quando empregados em um enunciado. Nesse sentido, convém observar como Bakhtin (2003) trata do "momento subjetivo do enunciado". Para o autor,

em cada enunciado [...] abrangemos, interpretamos, sentimos a intenção discursiva de discurso ou a vontade discursiva do falante [...]. Imaginamos o que o falante quer dizer, e com essa ideia verbalizada, essa vontade verbalizada (como a entendemos) é que medimos a conclusibilidade do enunciado. (BAKHTIN, 2003, p. 281)

A discussão implementada pelo autor reforça o caráter dinâmico de cada enunciado, pois o aspecto subjetivo que a interação propõe permite ao interlocutor avaliar as marcas que cada enunciado traz e, assim, emitir um juízo de valor, uma atitude, um posicionamento. Podese também refletir a respeito de que qualquer escolha linguística não acontece aleatoriamente, mas com base nos objetivos comunicativos que se pretende alcançar, sempre partindo de enunciados anteriores e nos conhecimentos compartilhados entre os participantes do evento linguístico. 
Levando-se em conta essas afirmações de Bakhtin, quando se trata de referenciação, é possível verificar que ela não se afasta da concepção interacionista da linguagem.

Primeiramente, cabe lembrar que a referenciação nem sempre foi interpretada dessa maneira. Estudos mais recentes apontam a diferença ao considerarem referência e referenciação. Segundo Mondada e Dubois (2003, p. 19), a referência "repousa sobre a hipótese de um poder referencial da linguagem que é fundado ou legitimado por uma ligação direta (e verdadeira) entre as palavras e as coisas" - ao passo que a referenciação se enquadra numa concepção de linguagem em que os sujeitos interagem entre si e com o meio para assim atribuir sentido ao mundo. Desse modo, para Mondada e Dubois (2003) a referenciação consiste em

práticas não imputáveis a um sujeito cognitivo abstrato, racional, intencional e ideal, solitário face ao mundo, mas a uma construção de objetos cognitivos e discursivos na intersubjetividade das negociações, das modificações, das ratificações de concepções individuais e públicas do mundo. (MONDADA; DUBOIS, 2003, p. 20)

Pode-se, a partir daí, pensar nos processos de referenciação e sua relação com a linguagem escrita. Conforme abordado na seção anterior, a linguagem escrita apresenta um papel importante na constituição da sociedade e dos sujeitos; portanto, as escolhas estratégicas e lexicais realizadas no momento de construção textual compreendem um recurso discursivo decisivo para que os objetivos comunicativos sejam atingidos.

Sendo assim, tem-se, no processo de referenciação, uma possibilidade de o sujeito apropriar-se da linguagem escrita e, dentro da perspectiva de negociação em que subjaz essa forma de linguagem, atingir suas intenções comunicativas. Da mesma forma, as escolhas linguísticas realizadas podem atuar na construção de valores individuais e coletivos.

Vista dessa forma, a referenciação corresponde a um processo de operacionalização da linguagem sob uma perspectiva sociocognitivo- 
interacionista, em que a escolha e a interpretação dos elementos linguísticos estão afetas às relações que se estabelecem entre os sujeitos histórica e socialmente situados. Isso ocorre em um processo de interação, exigindo desses sujeitos que sejam acionados certos conhecimentos necessários para a reconstrução dos sentidos.

Essa movimentação que caracteriza o processo de referenciação dentro do texto é compreendida por Francisco (2007, p. 170) como uma atividade "em que o referente, uma vez introduzido, pode ser reativado, revisto, redirecionado, fragmentado ou enriquecido, repensado e redefinido". Isso ocorre em função de objetivos discursivos e de conhecimentos compartilhados que se reúnem no decorrer do processamento textual.

A partir dessa visão, os referentes passam a ser considerados "objetos de discurso". De acordo com Roncarati (2010, p. 45), os "objetos de discurso" correspondem a

entidades que não são concebidas como expressões referenciais em relação especular com objetos do mundo ou com sua representação cognitiva, mas entidades que são interativamente e discursivamente produzidas pelos participantes no fio de sua enunciação. (RONCARATI, 2010, p. 45)

Koch (2008), seguindo a mesma perspectiva postulada por Mondada e Dubois (2003), aborda um aspecto relevante para esta análise, ao apontar a referenciação como uma "atividade discursiva". Para ela,

o sujeito, na interação, opera sobre o material linguístico que tem à sua disposição, operando escolhas significativas para representar estados de coisas, com vistas à concretização do seu projeto de dizer (Koch, 1999: 2002). Isto é, os processos de referenciação são escolhas do sujeito em função de um querer dizer. $(\mathrm{KOCH}$, 2008, p. 46)

Essa movimentação de elementos linguísticos e de estratégias dentro do universo textual em função de um "querer dizer" é 
compreendido no documento analisado sob a perspectiva dos objetivos reais do produtor do texto que busca persuadir seu interlocutor. Ao produzir o texto, o autor, reconhecido como o Bispo Dom Matheos, tem por objetivo orientar os párocos e a comunidade cristã quanto ao pagamento de mais um imposto à Igreja. A carta busca rebater as atitudes das autoridades que atuam contra o pagamento do tributo. Fica evidente que há uma situação de conflito entre as autoridades que administram a Vila de Antonina e a Igreja. A análise do excerto 1 possibilita essa constatação.

(1) $[. .$.$] chegamos ahum tempo taõ infelis edetantas$

Calamidades, que aquelles mesmos que por officio

eobrigaçaõ devem concervar nasociedade apás ecomunicaçaõ, os que fazem todo o exforço para perturbar

ames ma sociedade fomentando epatrocinando asmes

mas desordens em lugar deseconterem nos limites deseo poder $[\ldots]$

No exemplo 1, a introdução do objeto de discurso aquelles consiste no que Marcuschi (2008, p. 110) aponta como referenciação exófora com a utilização de um elemento gramatical. A interpretação desse elemento está relacionada a outros localizados fora do texto, exigindo do interlocutor a ativação de conhecimentos extralinguísticos para a obtenção do sentido.

O pronome aquelles, considerando a situação de conflito de interesses existentes na Vila, ao ser introduzido na carta, possibilita inferir que se trata das autoridades que estão agindo contra o pagamento dos tributos à Igreja. A opção pelo emprego desse elemento gramatical, em detrimento de outras formas que são utilizadas posteriormente no texto, pode ser vista como a expressão do desejo que o autor do texto tem em desqualificar as autoridades da época aos olhos do interlocutor.

A intenção do produtor do texto em menosprezar as autoridades faz com que o pronome aquelles apresente uma carga semântica negativa nesse caso. Assim, considera-se que a escolha foi realizada para atender aos propósitos de um determinado momento discursivo. Busca-se uma atitude favorável dos párocos e dos fiéis em relação às determinações da Igreja. 
Para que a referenciação atue estrategicamente na constituição de textos, Koch (2008, p. 33) destaca três formas de ocorrências envolvidas na constituição da memória discursiva: 1 - a construção/ ativação, que consiste na introdução de um objeto de discurso (novo ou por meio de anáforas associativas ou indiretas), o qual assume papel central dentro do modelo textual; 2 - a reconstrução/ reativação, que reintroduz um elemento presente na memória discursiva, por meio de uma forma referencial, mantendo o objeto de discurso já conhecido do interlocutor em foco; 3 - a desfocalização/ desativação, que compreende o fato de um objeto de discurso assumir a posição focal antes ocupada por outro, sendo que este permanece em "estado de ativação parcial", como aponta Koch, podendo retornar à posição anterior.

Quanto ao exemplo 1, verifica-se que, após a introdução ou ativação catafórica do objeto de discurso aquelles, ele será depois retomado e mantido em foco no texto por meio de elementos lexicais que geram uma recategorização. Segundo Roncarati (2010, p. 147), a recategorização corresponde a uma estratégia de referenciação que remete a um elemento já conhecido do interlocutor, agregando a ele novas propriedades ou características.

A recategorização, do ponto de vista discursivo, também pode ser avaliada como um recurso produtivo no que se refere às intenções de quem produz o texto. As novas propriedades apresentadas ao interlocutor podem atuar favoravelmente aos objetivos comunicativos do produtor textual. Trata-se de um procedimento argumentativo.

Retornando ao exemplo 1 , as recategorizações realizadas a partir do objeto de discurso aquelles podem atuar no sentido de informar ao interlocutor que autoridades estão sendo referidas pelo produtor do texto, como no caso de Camaras e de comandantes, verificados no excerto 2

(2) [...] Eporque odesaforo demuitas Camaras, eco mandantes tem chegado atal excesso que quizeraõ prender aos parochos, in juriando amuitos efaltando-lhe com o respeito devido, $[\ldots]$

Verifica-se que, nesse caso, a função é informativa. No entanto, a recategorização verificada com o objeto de discurso perturbadores doSucego 
publico, no trecho 3, exerce papel discursivo, pois dá ênfase às propriedades negativas das autoridades que a Igreja combate. Além disso, o emprego dessa expressão reafirma a importância da escolha realizada no exemplo 1. A opção do autor da carta em introduzir um objeto de discurso no texto por meio de elemento gramatical, que depois é remetido lexicalmente, revela a importância da seleção linguística e estratégica na construção textual. Considerando a interação entre produtor e interlocutor textual, o emprego de aquelles apresenta um peso maior naquele momento do discurso do que perturbadores doSucego publico.

(3) [...] Comunicarmos aos ecleziasticos da nossa Dioceze oque devia servir deexemplo acertos per-

turbadores doSucego publico que infringem as Leis;[...]

Koch também trata da especificidade do emprego de elementos anafóricos na produção textual. Segundo a autora, baseada em Berrendonner (1986),

o emprego de elementos anafóricos caracteriza-se como um fenômeno de retomada informacional relativamente complexa, em que intervém o saber construído linguisticamente pelo próprio texto e os conteúdos inferenciais que podem ser calculados a partir de conteúdos linguísticos tomados por premissas, graças aos conhecimentos lexicais, aos pré-requisitos enciclopédicos e culturais e aos lugares comuns argumentativos de uma dada sociedade. (KOCH, 2008, p. 47)

Essa afirmação ressalta a relação existente entre a linguagem e a sociedade. O documento analisado trata da oposição de interesses entre a Igreja e as autoridades, evidenciando-se uma disputa de poder entre as instituições. $\mathrm{O}$ emprego expressivo de retomadas anafóricas, por meio de sinônimos e reiterações para se referir ao clero, pode ser compreendido como uma forma de assegurar o poder que a Igreja detém naquele período da história, estando acima do próprio Rei.

Além de manter o foco no objeto de discurso, a aplicação repetitiva de elementos indicia a intenção do autor de destacar a 
autoridade do clero. Da mesma forma, a boa relação entre o clero e o governo maior sediado em Portugal é também reafirmada pelas reiterações constantes, quando o autor se reporta à realeza, já que a expressão Sua Alteza Real é retomada diversas vezes no decorrer do texto. Os trechos apresentados em 4 e 5 evidenciam a questão

(4) [...] por isso mandamos compena deexcomunhã̃ aos Muitos Reverendos Parochos naõ obe deçaõ aComandante algum nem as

Camaras noque estas mandarem sem que lhemostrem Ordem deSua Alteza Real, [...]

(5) [...] Comunicarmos aos ecleziasticos da nossa Dioceze oque devia servir deexemplo acertos perturbadores doSucego publico que infringem as Leis; eSefor necessario aos Muitos Reve rendos Parochos conçultarnos nestas mate rias podemfazer enos thedaremos os docu mentos necessarios [...]

Esse sentido é que os referentes podem ser reconhecidos como objetos de discurso. Conforme mencionado anteriormente, para Mondada e Dubois (2003, p. 20), a referenciação compreende uma estratégia de "construção de objetos cognitivos e discursivos na intersubjetividade das negociações, das modificações, das ratificações de concepções individuais e públicas do mundo". Portanto, os objetos de discurso são introduzidos e retomados no percurso textual, também em função de objetivos discursivos que englobam aspectos sociais, subjetivos e identitários.

Sendo assim, Koch (2008) destaca que a seleção linguística não ocorre eventualmente. O produtor do texto, a partir de suas percepções a respeito das condições comunicativas, como conhecimentos linguísticos, contexto, intenções, relações sociais e culturais, opera suas escolhas, visando minimizar equívocos de interpretação. Assim, constatase que, de fato, é em função de um "querer dizer" que a linguagem escrita é planejada. 
Ademais, a partir da concepção adotada por Bourdieu (1998), em que a linguagem, considerando também a escrita, pode ser interpretada como meio de manifestação de poder simbólico, salienta-se que o processo de referenciação textual também pode atuar de modo a representar esse poder. $\mathrm{O}$ trecho 6 demonstra que as relações entre os sujeitos não se dão meramente pela troca linguística, mas com base nas relações de poder existentes entre o bispo, o clero e a sociedade.

A seleção lexical e a estratégia de referenciação empregadas, nesse caso, podem ser vistas como expressão de autoridade dentro da hierarquia da Igreja, funcionando, de acordo com Bourdieu (1998), como um fator, ainda que não o único, dessa relação de poder simbólico que se dá na e pela linguagem.

(6) [...] pertendem ainda meter amaõ aoturibulo pa çando ordens edeterminaçoens ditadas todas porfim e paixoins particulares opóstas as pias intençoens eSabias determinaçoins deSua Alteza Real incaminhadas a perturbar aboa ordem eexcitar motins nos povos e perjudiciais a Real Fazenda julgando lizonjear os mesmos póvos comesta capa dezelo dobem publi co aomesmo tempo que infringem as Leis naturais divinas ebumanas que mandaõ dar oSus tento aos que trabalhaõ pois todo omercenario bedigno daSua paga enaõ sedeve fexar aboca aoBoi que lavra como dis a Escriptura principalmente aquelles quecontanto trabalbo morteficaçoins epe rigos daSua vida lheadministraõ opasto espiritu al vindo ainda mesmo porestes meyos afazer que os Póvos faltem aodevido respeito dos Superiores Ecleziasticos, comgrande desprezo das Leis Divinas edoSoberano que tanto maculaõ este, etaõ longe está deSer oSeo Zelo publico que osfas asim obrar oS eo ó= dio, efalta de Religiaõ, he tal que Sepossivel foce como outro Heliodoro despojariaõ os Altares doseo ornato eseasenhorariaõ dos depozitos Sagrados, eprivariaõ to talmente aos Ministros doSantuario daSua Subsis tencia fazendo porisso os povos infelizes eingratos a Deos pois tudo oque daõ para oAltar eSeos mi 
nistros he dado aDeos em agradecimento, eoSenhor Remunera com excesso euzura, osque asim ofazem con animo Sincéro, pelo que movidos nós destas Razo ins nos pareceo justo escrever esta Carta aos Muitos Reverendos Parochos [...]

Conforme já mencionado, o foco discursivo se mantém na disputa entre a Igreja e as autoridades que se posicionam contra o pagamento pelos fiéis de mais um tributo. $\mathrm{O}$ autor da carta busca defender a atitude da instituição Igreja, ao mesmo tempo em que procura denegrir a imagem das autoridades. Fatores precisamente religiosos não têm destaque na maior parte do texto.

Entretanto, no fragmento 6, há desfocalização do foco principal, no caso o pagamento de impostos à Igreja, e a introdução de um novo objeto de discurso Leis naturais divinas ehumanas, que representa a inserção do componente religioso no texto. A ativação desse objeto pode ser interpretada como uma estratégia discursiva, pois, retomando as considerações de Bazerman (2006), lembramos que a Igreja desenvolveu uma retórica específica para comunicar-se com os fiéis e com o próprio clero. O objetivo era estabelecer um vínculo com o interlocutor e, assim, obter dele cooperação.

Nesse sentido, a relação entre linguagem e sociedade fica evidenciada na abordagem que é apresentada por Bourdieu (1998). Para o autor, a linguagem consiste em um instrumento de "poder simbólico". É por meio dela que as representações são efetivadas e absorvidas pela sociedade. O "poder simbólico" revela-se, assim, sutilmente, nas práticas sociais por meio das diferentes formas de manifestação da linguagem, dentre elas a fala e a escrita. Pensar em escrita sob esse ponto de vista, como prática de "poder simbólico", sugere a reflexão sobre o seu papel na sociedade e nos conflitos/embates que podem surgir a partir disso.

Considerando o poder da instituição Igreja, verifica-se que o "poder simbólico" se manifesta de três formas distintas: o conhecimento do código, aspecto ainda precário no Brasil Colônia devido à ausência de um sistema de ensino organizado; o domínio da técnica da escrita, habilidade especialmente desenvolvida pelo clero; e o emprego de 
estratégias discursivas, que envolvem tanto a técnica da estruturação textual e as escolhas lexicais quanto artifícios de cunho social e cultural que ressaltam o poder da Igreja perante o governo e a sociedade.

Compreende-se que no texto analisado a estratégia de desfocalização, com a introdução do aspecto religioso, funciona como um meio para sensibilizar o interlocutor com relação às suas obrigações com Deus. Assim, os párocos devem atuar como sensibilizadores dos fiéis quanto à obrigação de pagar os impostos à Igreja.

Nos exemplos apresentados, procurou-se demonstrar que $\mathrm{O}$ processo de referenciação permite ao produtor atingir suas intenções, pois a seleção linguística é adequada ao propósito do autor do texto. Ao mesmo tempo, funciona como instrumento de ratificação da autoridade de uma instituição, e nesse caso a linguagem escrita reitera o poder da Igreja na sociedade da época.

Considerando a relevância dos documentos escritos para o período em que o texto foi produzido, pode-se afirmar que há estreita relação entre a escrita e a constituição da sociedade e dos sujeitos. Ela contribui para a consolidação de valores sociais e culturais, individuais, mas, principalmente, coletivos, e para determinação de formas de proceder com base em relações de poder que integram a sociedade

\section{CONSIDERAÇÕES FINAIS}

Não é possível ignorar a relevância social da escrita e o papel que ela desempenha na sociedade. A escrita pode ser interpretada como um obstáculo intransponível ou como um desafio encantador, a depender da forma como ela será vista e trabalhada a partir da iniciativa de estudiosos e educadores. Pensando na natureza social da escrita, buscou-se, com este trabalho, refletir a respeito da sua importância na constituição dos sujeitos e da sociedade, atuando como instituidora de valores e crenças individuais e coletivas.

Dentro dessa perspectiva, focalizaram-se os processos de referenciação textual como "prática simbólica" (MONDADA; DUBOIS, 2003) e como "prática discursiva” (KOCH, 2008). Assim, a referenciação 
é vista como um processo em que as escolhas linguísticas não ocorrem aleatoriamente, nem em relação direta com o mundo, mas na relação com o contexto e a situação de comunicação.

A referenciação, desse modo, se constrói na intersubjetividade entre os sujeitos. Sendo assim, os resultados obtidos com a análise do documento notarial apontam que as estratégias discursivas e a seleção lexical são fundamentais para que o produtor textual manifeste adequadamente suas intenções comunicativas. Observou-se que o autor da carta opera as escolhas que são apropriadas àquele momento discursivo, às suas intenções, buscando a cooperação do interlocutor com base em valores compartilhados.

Além de influenciar quem recebe o texto, a linguagem escrita, no caso das cartas notariais, atua diretamente sobre os fundamentos da sociedade. De acordo com os dados analisados, são ativados no texto elementos que ressaltam o poder da Igreja em relação às autoridades e à comunidade em geral. Esse domínio acarreta a determinação de maneiras de proceder da sociedade, cooperando para a representação da identidade de uma comunidade.

\section{REFERÊNCIAS}

BAKHTIN, M. M. Estética da criação verbal. Introdução e tradução de Paulo Bezerra. 4. ed. São Paulo: Martins Fontes, 2003.

BARONAS, J. E.; AGUILERA, V. de A. (Orgs.) Scripturae nas Villas de São Luiz de Goaratuba e Antonina: manuscritos setecentistas e oitocentistas. Londrina: Ed. UEL, 2007.

BAZERMAN, C. Gêneros textuais, tipificação e interação. DIONÍSIO, A. P.; HOFFNAGEL, J. C., (Orgs). Trad. e adaptação de Judith Chambliss Hoffnagel.São Paulo: Cortez, 2006.

BOURDIEU, P. A economia das trocas linguísticas: o que falar quer dizer. 2. ed. São Paulo: Ed. da Universidade de São Paulo, 1998.

FISCHER, S. R. Uma breve história da linguagem: introdução à origem das línguas. Tradução de Flávia Coimbra. São Paulo: Novo Século Editora, 2009. 
FRANCISCO, M. Maratona Atenas 2004: A (re)categorização em textos jornalísticos. D.E.L.T.A.,v. 23, n. 2, p. 167- 202, 2007.

GNERRE, M. Linguagem, escrita e poder. São Paulo: Martins Fontes, 2009. HIGOUNET, C. História concisa da escrita. Tradução de Marcos Marcionilo. São Paulo: Parábola Editorial, 2003.

KOCH, I. G. V. As tramas do texto. Rio de Janeiro: Nova Fronteira, 2008.

MARCUSCHI, L. A. Produção textual, análise de gêneros e compreensão. São Paulo: Parábola, 2008. Cortez, 2010.

Da fala para a escrita: atividades de retextualização. 10. ed. São Paulo,

MONDADA, L.; DUBOIS, D. Construção dos objetos de discurso e categorização: Uma abordagem dos processos de referenciação. In: CAVALCANTE, M. M.; RODRIGUES, B. B.; GIULLA, A. (Orgs). Referenciação. São Paulo: Contexto, 2003. P. 17-52.

OLSON, D. R. O mundo no papel: as implicações conceituais e cognitivas da leitura e da escrita. Tradução: Sérgio Bath. Revisão técnica: Rodolfo Ilari. São Paulo: Ática, 1997.

; TORRANCE, N. Cultura escrita e oralidade. Tradução de Valter Lellis Siqueira. 2. ed. São Paulo: Ática, 1997.

RONCARATI, C. As cadeias do texto: construindo sentidos. São Paulo: Parábola Editorial, 2010.

STREET, B. What's "new" in New Literacy Studies? Critical approaches to literacy in theory and practice. Current Issues in Comparative Education, Teachers College, Columbia University, v. 5, n. 2, p.77-91, may 2003.

\section{ANEXOS}

$\mathrm{N}^{\circ}$ Doc: 12 [437]

Composição: fólio $2 \mathrm{v}$

Assunto/resumo: Trata do pagamento de vários impostos à Igreja pelos fiéis.

Datação: 26/abril/1803

Autor: Manoel Baldoino Lopez. 
$<$ Carta do Excelentissimo> Muitos Reverendissimos Senhores Vigarios, Meos $<$ Senhor Bispo $>$ amados Irmaons Collegas, e coperadores do nosso Minis Terio chegamos ahum tempo taõ infelis edetantas Calamidades, que aquelles mesmos que por officio eobrigaçaõ devem concervar nasociedade apás ecomu nicaçaõ, os que fazem todo o exforço para perturbar ames ma sociedade fomentando epatrocinando asmes mas desordens em lugar deseconterem nos limites deseo poder pertendem ainda meter amaõ aoturibulo pa çando ordens edeterminaçoens ditadas todas porfim e paixoins particulares opóstas as pias intençoens eSabias determinaçoins deSua Alteza Real incaminhadas a perturbar aboa ordem eexcitar motins nos povos e perjudiciais a Real Fazenda julgando lizonjear os mesmos póvos comesta capa dezelo dobem publi co aomesmo tempo que infringem as Leis naturais divinas ehumanas que mandaõ dar oSus tento aos que trabalhaõ pois todo omercenario hedigno daSua paga enaõ sedeve fexar aboca aoBoi que lavra como dis a Escriptura principalmente aquelles quecontanto trabalho morteficaçoins epe

\begin{tabular}{|l|}
\hline$N^{\circ}$ Doc: $12[438]$ \\
\hline Composição: fólio $3 \mathrm{r}$ \\
\hline Assunto/resumo: Trata do pagamento de vários impostos à Igreja pelos fiéis. \\
\hline Datação: 26/abril/1803 \\
\hline Autor: Manoel Baldoino Lopez. \\
\hline
\end{tabular}

rigos daSua vida lheadministraõ opasto espiritu al vindo ainda mesmo porestes meyos afazer que os Póvos faltem aodevido respeito dos Superiores Ecleziasticos, comgrande desprezo das Leis Divinas edoSoberano que tanto maculaõ este, etaõ longe está deSer oSeo Zelo publico que osfas assim obrar oSeo ó= dio, efalta de Religiaõ, he tal que Sepossivel foce como outro Heliodoro despojariaõ os Altares doseo ornato eseasenhorariaõ dos depozitos Sagrados, eprivariaõ to talmente aos Ministros doSantuario daSua Subsis tencia fazendo porisso os povos infelizes eingratos a 
Deos pois tudo oque daõ para oAltar eSeos mi nistros he dado aDeos em agradecimento, eoSenhor Remunera com excesso euzura, osque asim ofazem con animo Sincéro, pelo que movidos nós destas Razo ins nos pareceo justo escrever esta Carta aos Muitos Reverendos Parochos para que cada hum faça todo oexforço porconcervar os Seos direitos enaõ prejudi car aos Seos Sucessores arecadando todas as conhecen ças Segundo os uzos que Seacharaõ estabalecidos nas Suas Igrejas pois para isso temos hum avizo deSua Alteza Real que nos manda concervemos todos os uzos eCostumes praticados nonosso Bis pado, que forem conformes ao Bispado do Rio de Ianeiro, ecomo para nos Certificarmos dos daquelle Bispado mandamos ahi tirar certidoins dosmes mos uzos eCostumes, eestas uniforrmemente di gaõ que em todas as Igrejas domesmo Bispado do Rio ou Sejaõ colladas ou naõ pagaõ conhecenças aos Muitos Reverendos Parochos, alem deSeprovar esta materia por muitas Sentenças dadas naRelação do mesmo Rio de Janeiro afavor dos Muitos Reverendos Parochos Sobre as conhecenças eesta mesma pratica seobserva nas Igrejas Colladas deminasgerais eainda mesmo neste nosso, nas Igrejas Colladas, e nos mais Bispados da America, collegindose esta mesma verdade daCarta Regia que Sua AltezaReal foi Servido escrevernos para pór em Concurso as Igrejas deste Bispado pela qual nos derigimos nainformaçaõ que démos domes mo Senhor das Conhecenças, epé de altar

\begin{tabular}{|l|}
\hline $\mathrm{N}^{\circ}$ Doc: $12[439]$ \\
\hline Composição: fólio $3 \mathrm{v}$ \\
\hline Assunto/resumo: Trata do pagamento de vários impostos à Igreja pelos fiéis. \\
\hline Datação: 26/abril/1803 \\
\hline Autor: Manoel Baldoino Lopez. \\
\hline
\end{tabular}


de altar para a vista do Rendimento dassimualquer Igre ja Sua Alteza Real determinou huma Congroa Sus tentação aos Muitos Reverendos Parochos dando acon nhecer Sua Alteza Real nas nossas Informaço ins que Sem as Conhecenças os Muitos Reveren dos Parochos naõ poderaõ Sustentarse onesta mente sinaõ comhuã Congroa demais detre zentos mil Reis pagos da Fazenda Real, eco moSua Alteza Real tem determinado Sem mil reis para cada muito Reverendo Parocho claro está que tacitamente aprova as conhecenças emais direitos ealem disto muitos que prezumen interpretar odireito fazendo diferenças de conhe cenças aAlelluýas Seenganaõ porque hũa eoutra couza Saõ oblaçoins para asusten taçaõ dos menistros doSantuario as quais devoluntarias em outro tempo paçavaõ nece ssarias, eestas mesmas sepagaõ em todos os Bis pados doReino como nos Sabemos pela mes ma experiencia deParochos que fomos em duas Igrejas dobispado de Coimbra com onome de Conhecenças fulares, ainda que come cemos osdezimos, he pois concludente que as conhecenças devem Ser pagas aos Muitos Reve rendos Parochos Segundo os uzos estabelecidos em Cada húa das Igrejas recomendamos pois aos Muitos ReverendosParochos Cobrem as suas Conhecenças uzandodetoda prudencia emode raçaõ atendendo apobreza, lembrados doque dis Iesus Christo, misericordiam volo, et non sacrifiti um, eque naõ he ambiçaõ oque nos fás asim obrar mas Sim a necessidade da nossa honesta Sustentaçaõ havendoporem alguns que poçaõ pa gar bem que porteimósos epertinazes onaõ queiraõ fazer uzem para com elles dos meyos daIustiça enaõ tendo provimento agravem para aRela çaõ doRio dejaneiro ainda mesmo contra as Ca maras eoutras quais quer pessoas quelhe quei- 


\begin{tabular}{|l|}
\hline $\mathrm{N}^{\circ}$ Doc: $12[440]$ \\
\hline Composição: fólio $4 \mathrm{r}$ \\
\hline Assunto/resumo: Trata do pagamento de vários impostos à Igreja pelos fiéis. \\
\hline Datação: 26/abril/1803 \\
\hline Autor: Manoel Baldoino Lopez. \\
\hline
\end{tabular}

queiraõ impidir e embaraçar seos direitos.

Eporque odesaforo demuitas Camaras, eco

mandantes tem chegado atal excesso que qui-

zeraõ prender aos parochos, in juriando amui-

tos efaltando-lhe com o respeito devido, para

pois vermos Sepodemos dar Remedio a estes

males taõ contrarios, eopostos as Leis doSobe-

rano visto que osmeyos que procuramos

com toda aSubmiçaõ naõ tiveraõ efeito por

isso mandamos compena deexcomunhaõ

aos Muitos Reverendos Parochos naõ obe

deçaõ aComandante algum nem as

Camaras noque estas mandarem sem que

lhemostrem Ordem deSua Alteza Real, ou

nossa para asim omandarem naõ lhefaltan

do com aobediencia devida, pois nós Sós Somos

os Iuizes Privativos dos ecleziasticos eSua

AltezaReal Seguindo as pias determinaço

ins detodos os monarcas Catholicos nogover

nos Eccleziasticos danossa Dioceze digo Ecle

ziasticos manda-nos aSuas ordens para as

Comunicarmos aos ecleziasticos da nossa Dio-

ceze oque devia servir deexemplo acertos per-

turbadores doSucego publico que infringem

as Leis; eSefor necessario aos Muitos Reve

rendos Parochos conçultarnos nestas mate

rias podemfazer enos thedaremos os docu

mentos necessarios eainda mesmo nós jun-

tos daremos aSua Alteza Real conta acrecen-

tandonella as vexaçoins que este mizera

vel povo Sófre etem Sofrido pois temos o

brigaçaõ deprocurar afelescidade delle; Esta 
Carta naõ he necessario ir para as Freguezias que temos nas Freguezias de Minas gerais, pois ali tem dado todas as nece ssarias ejusticimas providencias o Illus-

$\mathrm{N}^{\circ}$ Doc: 12 [441]

Composição: fólio $4 \mathrm{v}$

Assunto/resumo: Trata do pagamento de vários impostos à Igreja pelos fiéis.

Datação: 26/abril/1803

Autor: Manoel Baldoino Lopez.

o Illustricimo eExcellentissimo Senhor Bernar

do Jose deLorena, este grande general taõ aman te daRelegiaõ que tanto respeita aos Ecleziasticos taõ observante das Leis doSoberano, e taõ Zeloso dobem publico, basta para Seo Elogio dizerse queSua Alteza Real por Seo Decreto opoem como Mestre para dar as Suas Sabias instruçoins aos Generais. Dada em Saõ Paulo aos Seis deNovembro de mil oito centos edous. Dom Matheos Bispo Villa de Castro $=$ Santo Antonio da Lapa $=$ Saõ Jose $=$ Coritiba $=$ Antonina $=$ Parnagoa Cananea $=$ Iguape $=$ Conceiçaõ de Itanhaen Esta Carta Circulara as Igrejas Supra. Naõ Secontinha mais em adita Carta que fica rezistada em livro competente. Item Certefico mais que nodia vinte equatro deAbril deste prezente anno, naextaçaõ daMiça conventual, publicou oReverendo Vigario desta villa que os moradores, della eos mais seos feguezes levasem os seosbilhetes dedezobrigar, e taõ bem os seos ordenados todo oreferido heverdade porque prezente meachei napublicaçaõ, eemfe deque paço aprezente pormim asignada Villa Antonina 26 deAbril de 1803. Manoel Baldoino Lopez 
Recebido em: 12/07/11. Aprovado em: 11/03/12.

Title: A look on written language and the process of referentiation in notarized letters Authors: Jaqueline Aparecida dos Santos Dutra; Elódia Constantino Roman

Abstract: To be able to write in a proficient way, it is not enough to see writing as a communication tool, since the process of appropriation of language through writing involves many aspects beyond the knowledge of the alphabet or the mastery of technique. The objective of this paper is to discuss the importance of writing in the constitution of subjects and of society. The focus is on language choices and strategies of textual referentiation used in a notarized letter written in the year 1803. Based on Fisher (2009), Olson (1997), Bourdieu (1998), Dubois \& Mondada (2003), Koch (2008), among others, it was observed that writing is understood from different perspectives. The results show that the lexical selection in language writing is performed based on the intentions of the author of the text before his/her interlocutor. Likeevise, it sets up individual and collective beliefs.

Keywords: Written language. Social practice. Referentiation.

Titulo: Una mirada sobre el lenguaje escrito y los procesos de referencia en cartas notariales Autores: Jaqueline Aparecida dos Santos Dutra; Elódia Constantino Roman

Resumen: Para un trabajo satisfactorio con la escritura, no basta tenerla solamente como instrumento de comunicación, visto que el proceso de apropriación del lenguaje por medio de la escritura envuelve muchos aspectos además del conocimiento del alfabeto o el dominio de la técnica. Así, el objetivo de este trabajo es reflexionar sobre la importancia de la escritura en la constitución de los sujetos y de la sociedad. El foco está en las elecciones lingüisticas y en las estrategias de referencia textual empleadas en la construcción del documento denominado carta notarial, producido en el año de 1803. Con base en Fisher (2009), Olson (1997), Bourdieu (1998), Mondada \& Dubois (2003), Koch (2008), entre otros, se observó como la escritura es comprendida bajo diferentes perspectivas. Los resultados obtenidos revelan que la selección lexical en el lenguaje escrito es realizada con base en las intenciones del autor del texto ante su interlocutor. De la misma forma, actuan como elementos instituidores de valores y creencias individuales y colectivas.

Palabras-clave: Lenguaje escrito. Práctica social. Referencia. 